\title{
EXPERIMENTAL INVESTIGATION ON AGEING BEHAVIORS OF RUBBERS USED FOR BRIDGE BEARINGS
}

\author{
Yoshito ITOH${ }^{1}$, Haosheng GU², Kazuya SATOH${ }^{2}$ and Yukihiro KUTSUNA ${ }^{3}$ \\ ${ }^{1}$ Fellow Member of JSCE, Professor, Dept. of Civil Eng., Nagoya University \\ (Furo-cho, Chikusa-ku, Nagoya 464-8603, Japan) \\ E-mail:itoh@civil.nagoya-u.ac.jp \\ ${ }^{2}$ Student Member of JSCE, Dept. of Civil Eng., Nagoya University \\ (Furo-cho, Chikusa-ku, Nagoya 464-8603, Japan) \\ E-mail:hausn@civil.nagoya-u.ac.jp \\ ${ }^{3}$ Member of JSCE, Construction Department 2, Japan Highway Public Corporation Chubu Branch \\ (Sumitomo Mitsui Bank Bld., 2-18-19, Nishiki, Naka-ku, Nagoya 460-0003, Japan) \\ E-mail: yukihiro.kutsuna@jhnet.go.jp
}

\begin{abstract}
In order to evaluate the deterioration characteristics during the lifecycle of bridge rubber bearing, a series of long-term accelerated exposure tests are performed on four kinds of rubber materials widely utilized for bridge bearings. Different degradation factors are applied in these tests, such as thermal oxidation, ozone, low temperature ozone, ultraviolet radiation, salt water and acid rain. The test duration lasts from 96 hours to more than 6,000 hours. Mechanical properties of aged rubber specimens are measured and compared. The effects of pre-strain are investigated too. The ageing behaviors of each kind of rubber are made clear. The test results are fundamental to the prediction of rubber bearings' durability.
\end{abstract}

Key Words : rubber bearing, ageing behavior, mechanical property, pre-strain

\section{INTRODUCTION}

Rubber is an ideal material to withstand large deformation and absorb energy because of its high elasticity, high damping and large elongation at failure. Although rubber was firstly used as load bearing pads supporting a railway viaduct constructed in 1892 in Meblourne, Australia, it was more than half a century later before rubber bearings moved into the mainstream of structural engineering. The laminated rubber bearings have been developed to support bridge decks since about 1957. During the 1960's laminated rubber bearings were also modified for use as building supports. In order to add energy dissipation to the flexibility already exists, the lead rubber bearing (LRB) was invented in the 1970's. In the early 1980's development in rubber technology led to new rubber compounds, which were termed high damping rubber (HDR). Nowadays, rubber bridge bearings have been adopted worldwide as an effective means to reduce the seismic response of the structures. While in Japan, since the 1995
Hyogoken-Nanbu earthquake, the great damage of the bridges using steel bearings has made people recognize the significance of more reliable anti-earthquake devices. And up to now, the rubber bearings are being used in more than 1,000 bridges.

The ageing problems of the rubber materials have been studied for some years. Blackman and $\mathrm{McCall}^{1)}$ studied the relationship between the thermal ageing and the physical properties, and suggested the cross-link degradation processes might contribute to the deterioration in physical properties of the vulcanizate. Braden and Gent ${ }^{2)}$ have defined the characteristics of static crack growth due to ozone. An attempt has been made by Sugimoto et al. ${ }^{3)}$ to find out the mechanism of ozone cracking under low environmental temperature. Koike et al. ${ }^{4)}$ conducted accelerated artificial weathering tests on rubber and plastic sheets to estimate the effects of heat and light. Some methods for prediction of the long-term mechanical behavior and lifetime of polymeric materials were discussed by Song et al. ${ }^{5)}$. Wei et al. ${ }^{6}$ ) also investigated the dynamic mechanical properties of 
aged rubbers through experiment. Rubber is a hydrocarbon built up of regular sequences of macromolecule ${ }^{7)}$. The macromolecule is arranged in cis-configuration, forming long chains of high elasticity, which are kinked in the material. By vulcanizing sulfur cross-links are established between chains and a coherent network is formed. If subjected to oxidation, the cross-links will break up, the chains will re-entangle and form more new cross-links ${ }^{8}$. With the increase of cross-links the network becomes tighter and the motion of the chains become more impeded, which result in high hardness, low elongation and brittle fracture of the material.

However, compared with the rubbers for tyres, seals and mounts, the long-term properties of rubbers used for bridge bearings are seldom investigated because of their limited application history. During the design process the long-term properties of rubber bearing are usually neglected, although rubber materials are exposed to variant environments and attacked by different degradation factors such as oxidation, ultraviolet radiation, ozone, temperature, acid and humidity. Even if the designed rubber bearing satisfies the code requirements, it is hard to say the future performance after 50 or 100 years can still be secured. And nowadays the cost of rubber bearing accounts for about $5 \sim 10 \%$ of the total cost of a bridge. It is necessary to take the lifecycle of rubber bearing into consideration in order to reduce unnecessary replacement cost. The lifecycle analysis requires an explicit understanding of the durability of each material. Therefore, the effects of different degradation factors on rubber material's characteristics must be found out. Besides, there are more than one kind of rubber material widely used as components of bridge bearings, and the ageing behaviors of different materials should also be different. The investigation of these differences helps gain valuable insight into the durability of different materials. Moreover, under the vertical load induced by the superstructure as well as vehicles, the brims of the rubber layers bloom outwards and exhibit tensile stresses as a result of incompressible behavior of rubber materials. The influence of the tensile stresses on rubbers' ageing behaviors is also worth studying.

Itoh et al. ${ }^{9}$ have done a series of accelerated exposure tests on Natural Rubber (NR) and Chloroprene Rubber (CR). The deterioration characteristics of those two kinds of rubbers were clarified under the environments of thermal oxidation, ozone, low temperature ozone, ultraviolet radiation, salt water and acid rain. It was found that the deterioration effects due to thermal oxidation and ultraviolet radiation are severer than other factors. The purpose of this research is to investigate the environmental effects on other popular rubber materials used for bridge bearings in Japan. In this research, there are four kinds, six types of rubber materials provided by five largest companies in Japan, almost covering all the rubber materials usually used for bridge bearings. Six same kinds of long-term accelerated exposure tests are performed. The ageing time is chosen to be $96 \sim 6,144$ hours. The rubber specimens are stretched to the strains of $0 \%, 20 \%$ and $40 \%$ and the pre-strains are kept throughout the tests to investigate the pre-strain influences. The stresses at certain strains, elongation at break and tensile strength are measured through the uniaxial tensile experiment. The variations of the mechanical properties over the ageing time under different pre-strains are experimentally studied. The effects of different degradation factors as well as the pre-strain are evaluated for each rubber and compared among those rubber materials.

\section{ACCELERATED EXPOSURE TESTS}

\section{(1) Materials and specimens used in accelerated exposure tests}

Four kinds of rubber materials often used as components of bridge rubber bearings are tested in this research, and they are Natural Rubber (NR), Chloroprene Rubber (CR), Ethylene-Propylene Rubber (EPDM) and High Damping Rubber (HDR). From a chemical point of view the main part of NR is a polymeric hydrocarbon, where every molecule contains thousands of isoprene units, which are described by the chemical formula $\left(C_{5} H_{8}\right)_{\mathrm{n}}$. The isoprenes arrange in cis-configuration, forming long chains of high elasticity. It has very good resistance to abrasion and fatigue, but poor resistance to ozone (weather), oils and fuels. To improve properties, NR is often reinforced by particulate fillers, such as carbon black and silica. Chloroprene rubber consists solely of polymerized chloroprene monomers, and it has a generally good balance of mechanical properties and fatigue resistance second only to NR. The polymer has a good resistance to the outdoor climate as well as reasonable oil resistance. Ethylene-propylene rubber, with the abbreviation EPDM, consists of ethylene, propylene and diene. EPDM has excellent resistance to atmospheric ageing, oxygen and ozone up to about $150^{\circ} \mathrm{C}$. In the manufacture of HDR, NR is vulcanized together with carbon black, plasticizer, oil, and so on. Consequently, the rubber possesses specific characteristics such as maximum strain dependency of stress evolution, energy absorbing properties and hardening properties.

The test specimens made of rubber materials mentioned above are provided and tested by five main rubber companies in Japan. These four kinds of rubbers almost cover all the rubber materials used 
presently for bridge bearings. Among them three types of NR are tested. According to the different additive compositions, they are named as NR_A, NR_B and NR_C. For the business reason, the details of rubber compound formulations are kept confidential. In all the accelerated exposure tests, the No.3 dumbbell specimens specified by JIS K 6251 are used. As shown in Fig.1, the dumbbell-like specimen with a thickness of $2 \mathrm{~mm}$ is designed for the tensile test. The middle part with a width of $5 \mathrm{~mm}$ and a length of $20 \mathrm{~mm}$ is applied to evaluate the deterioration characteristics. The samples are sufficiently thin to avoid diffusion-limited oxidation effects during the experiment.

It is found that the outer surface the rubber layer between steel plates will bloom outwards when the bearing subjected to the compressive dead and live loads, as shown in Fig.2. That is to say, the brim of the rubber layer is in tensile state. Both the compressing test and the FEM simulation prove that the maximum tensile strain at the side surface of the rubber bearing can reach $40 \%{ }^{10),}{ }^{11)}$. In order to simulate the real state of the rubber bearing in service, the specimens are stretched to certain strains using a special rig shown as Fig.3. In the accelerated exposure tests the pre-strains are set as $0 \%, 20 \%$ and $40 \%$ to investigate the influence of the combination of tensile strain and degradation factors. Considering the large deviation of the test results even from the same rubber material, for each degradation factor, each pre-strain state and each measuring time, 12 samples are prepared. Except for the specimens in the

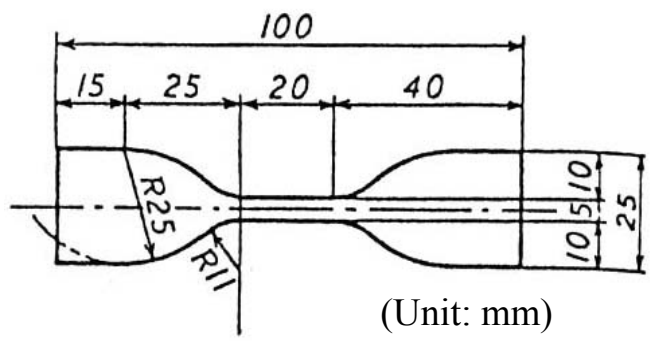

Fig.1 JIS No.3 dumbbell specimen virgin state, for each type of rubber (NR_A, NR_B, NR_C, CR, EPDM, and HDR), there are $(7+5+5+3+3+3) \times 3 \times 12=936$ test pieces, and in total there are 5,688 specimens.

\section{(2) Accelerated exposure test conditions}

In this research, six kinds of environmental conditions are simulated by the accelerated exposure tests shown in Table $\mathbf{1}^{12)}$. They are thermal oxidation test, $40^{\circ} \mathrm{C}$ ozone deterioration test, low-temperature ozone deterioration test, weather resistant test, salt water mist combined cycle test and acid rain mist combined cycle test, as shown in Fig.4. The test conditions are much severer than the real environment conditions in order to investigate the long-term characteristics within the limited time. The details of these test conditions are presented as follows.

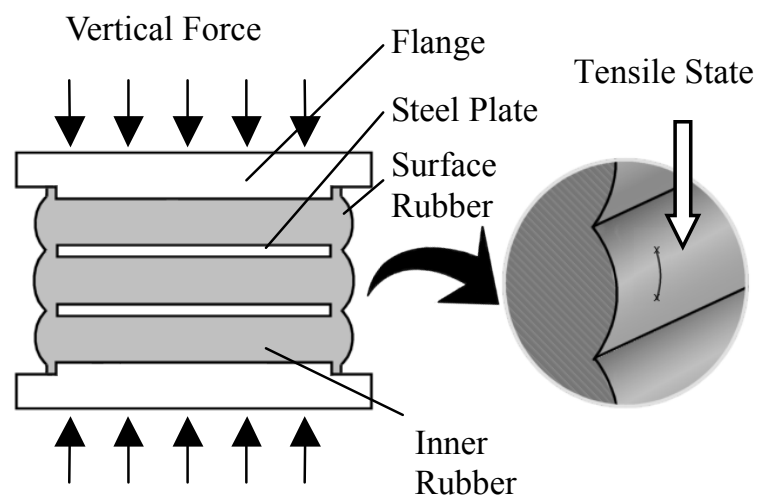

Fig.2 Strain on the bearing surface

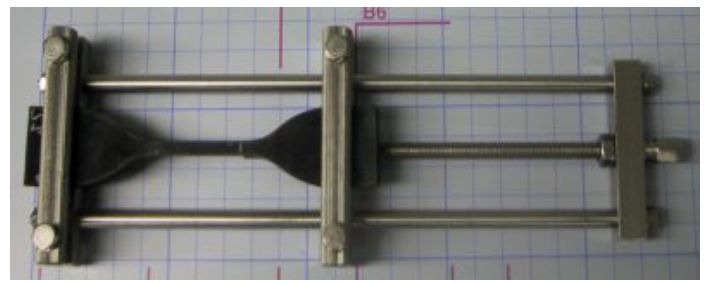

Fig.3 Pre-straining rig

Table 1 Conditions of accelerated ageing test

\begin{tabular}{|c|c|c|c|c|}
\hline Material & Pre-strain & Degradation factor & Test condition & Time (hours) \\
\hline \multirow{3}{*}{$\begin{array}{c}\text { NR, } \\
\text { CR, }\end{array}$} & & Thermal oxidation & $70^{\circ} \mathrm{C}$ & $96,192,384,768,1536,3072,6144$ \\
\cline { 2 - 5 } EPDM, & Ozone & Ozone $=0.5 \mathrm{ppm}, 40^{\circ} \mathrm{C}$ & $96,192,384,768,1536$ \\
\cline { 2 - 5 } HDR & $0,20,40 \%$ & Low-temperature ozone & Ozone $=0.5 \mathrm{ppm},-30^{\circ} \mathrm{C}$ & $96,192,384,768,1536$ \\
\cline { 2 - 5 } & & Ultraviolet radiation & Radiation and water spray & $360,720,1440$ \\
\cline { 2 - 5 } & & Salt water spray & Wetting and drying cycle & $360,720,1440$ \\
\cline { 2 - 5 } & Acid rain spray & Wetting and drying cycle & $360,720,1440$ \\
\hline
\end{tabular}




\section{a) Thermal oxidation test}

The thermal ageing of the specimens is carried out in a temperature-controlled air-ageing oven. High temperature can accelerate the chemical reactions, however, it is said that the temperature can affect the tendency of the property change. For example, NR undergoes predominant chain scission above $80^{\circ} \mathrm{C}$, but below $80{ }^{\circ} \mathrm{C}$ it cross-links ${ }^{13)}$. So the environmental temperature in the test is controlled as $70^{\circ} \mathrm{C}$ to avoid unexpected chemical reactions. The test follows the method of ageing test on vulcanized rubber specified by JIS K 6257 . The specimens are taken out for measurement at 96 hours, 192 hours, 384 hours, 768 hours, 1,536 hours, 3,072 hours and 6,144 hours (about 8.5 months).

\section{b) Ozone test}

The most commonly used method of judging the resistance of the rubber material to the attack by the ozone is by exposing stretched strips of rubber to a higher concentration of ozone than the product is expected to meet in its life. According to the ozone test method specified by JIS K 6259 aiming at the vulcanized rubber and the requirements by the Construction Management Specification of Japan Highway Public Corporation (JH), the concentration of ozone is set as $0.5 \mathrm{ppm}$ and the environmental temperature is controlled to be $40^{\circ} \mathrm{C}$. The whole test lasts 1,536 hours (about 64 days). The specimens are taken out for observation at the time in Table 1.

\section{c) Low-temperature ozone test}

In the low-temperature ozone test the temperature is set as $-30^{\circ} \mathrm{C}$, and other conditions are the same as the ozone test in $40^{\circ} \mathrm{C}$.

\section{d) Weather resistant test}

The weather resistant accelerated test is designed to reflect the influence of the sunlight irradiating the rubber material. A carbon arc light can produce artificial ultraviolet radiation $\left(425 \mathrm{~W} / \mathrm{m}^{2}, 300 \sim\right.$ $700 \mathrm{~nm}$ ) covering the main wavelength region of the sunlight ultraviolet. The test machine is called Dew Cycle Sunshine Weather Meter (S80D) produced by SUGA Test Instruments Co.. The cycle composed of 60 minutes of irradiation and 30 minutes of pure water spaying is adopted. The temperature and humidity inside the chamber can be controlled automatically. During the irradiation process, the black panel temperature (BPT) is controlled as $63 \pm$ $3^{\circ} \mathrm{C}$, the chamber temperature is $50 \pm 2^{\circ} \mathrm{C}$, and the humidity is $50 \pm 3 \%$. During the water spraying process, the irradiation stops. The chamber temperature is kept as $30 \pm 2^{\circ} \mathrm{C}$, and the humidity is $98 \pm 3 \%$. The durations of this test are 360 hours, 720 hours and 1,440 hours (60 days).

e) Salt water mist combined cycle test

The salt water mist combined cycle test uses the

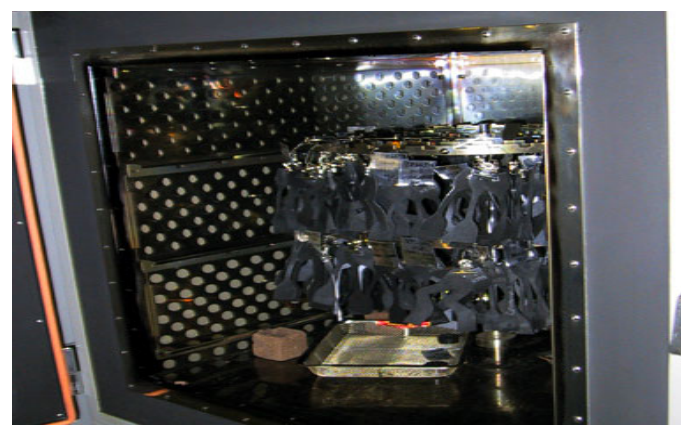

(a) Thermal oxidation test

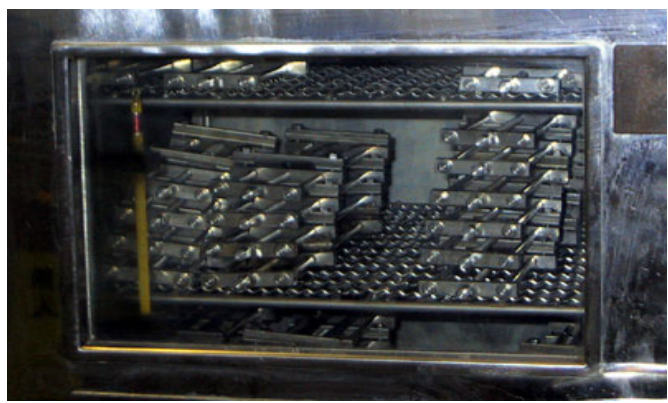

(b) Ozone test/ Low-temperature ozone test

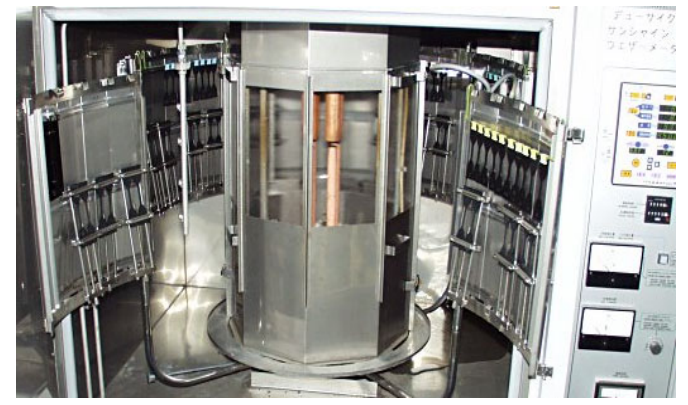

(c) Weather resistant test

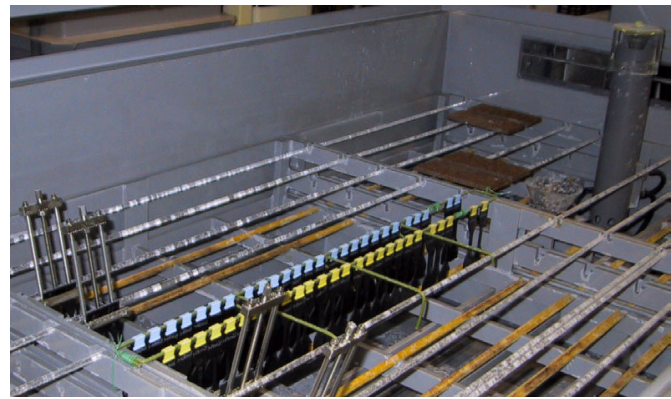

(d) Salt water and acid rain mist combined cycle test

Fig.4 Accelerated exposure tests

S6-cycle, which is proposed by the Ministry of International Trade and Industry and is specified in JIS K 5621 to test the corrosion resisting ability of the steel coating systems. The S6-cycle consists of 30 minutes of salt water spraying $\left(30 \pm 2{ }^{\circ} \mathrm{C}, 98 \%\right), 90$ minutes of wetting $\left(30 \pm 2^{\circ} \mathrm{C}, 95 \%\right), 120$ minutes of drying by hot wind $\left(50 \pm 2{ }^{\circ} \mathrm{C}, 20 \%\right), 120$ minutes of 
drying by warm wind $\left(30 \pm 2{ }^{\circ} \mathrm{C}, 20 \%\right)$. A Combined Cyclic Corrosion Test Instrument (CYP200) made by SUGA Test Instruments Co., Ltd. is used to simulate the cyclic deterioration environment. This equipment can operate automatically and control the conditions of salt water atomizing, temperature, and humidity in arbitrary order and combinations. The measuring time is the same as the weather resistant test. The concentration of the salt water is $5 \%$.

\section{f) Acid rain mist combined cycle test}

Because rubber will react with acid, it is needed to clarify this deterioration mechanism. Using the same cycle as the salt water mist combined cycle test, the acid rain mist combined cycle test just replaces the $5 \%$ salt water by pH3.5 acid fluid and keeps other conditions unchanged. The acid fluid is made from sulfuric and nitric acid.

\section{(3) Mechanical property inspection method}

The uniaxial tensile experiment is performed to investigate the mechanical properties of the aged rubber specimens. The inspection method conforms to the quality inspection method specified by $\mathrm{JH}$ as well as the specifications in JIS K6251 and K6253 about the general rules of physical testing methods for vulcanized rubber. Because the stress-strain relationship of rubber material shows high non-linearity, it is difficult to calculate the stiffness using the secant method. For all the aged rubber samples, the stresses at $25 \%, 50 \%, 100 \%, 200 \%$ and $300 \%$ strain, i.e. M25, M50, M100, M200 and M300, the elongation at break (EB) and tensile strength (TS) are taken as the evaluation indexes. Every time there are 12 specimens taken out and measured. The average values with the double of the standard deviations $(M \pm 2 S)$ are illustrated.

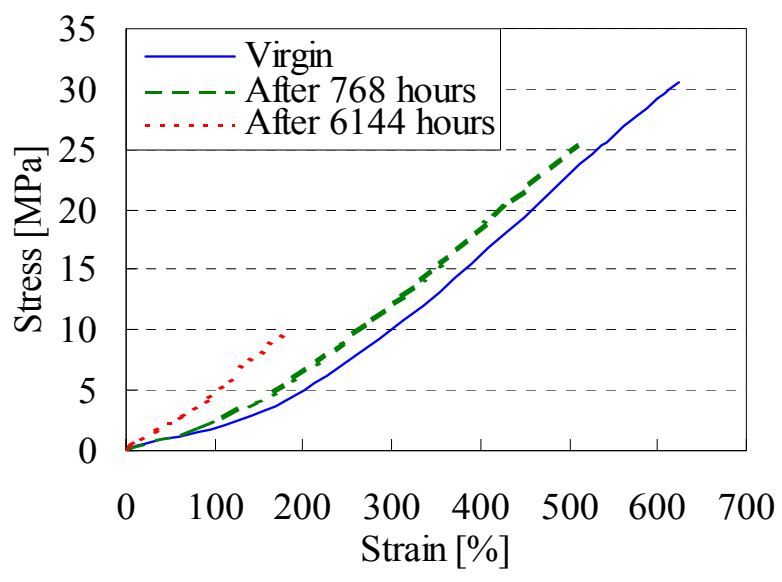

Fig. 5 Stress-strain relationship of NR in thermal oxidation (pre-strain $=0 \%$ )

\section{TEST RESULTS AND DISCUSSIONS}

\section{(1) General ageing behaviors}

Fig.5 shows the typical stress-strain curves obtained through the uniaxial tensile experiment. Basic mechanical properties such as modulus, tensile strength and elongation at break, etc. can be determined from these curves. It can be seen that the stress-strain relationships are not linear. The stiffness of the rubber material cannot be evaluated by the secant stiffness directly. For this reason the stresses corresponding to some defined strains are measured to reflect the stiffness of rubber. With the thermal ageing progressing, the stresses corresponding to the defined strains increase, while tensile strength and elongation at break decrease. In other words, rubber becomes harder and more brittle. For the four kinds of rubber materials investigated in this research, this tendency seems to be almost the same. The hardening effect will reduce the ability of deforming and absorbing energy. Meanwhile, the brittleness will lower the safety of rubber bearing.

\section{(2) Strain dependency}

Because the stress-strain relationship of the rubber materials is not linear, the change rates of M25, M50, M100, M200 and M300 are not the same. Fig.6 shows the strain-dependent effect of the aged rubber samples. The stresses at some certain strains are normalized by taking the corresponding stresses of the original samples as one. For simplicity, the average values of the 12 samples with the double of the standard deviation $(\mathrm{M} \pm 2 \mathrm{~S})$ are illustrated on EPDM because the deviation of EPDM is the largest among theser six rubbers.

It can be seen that after about 2 months' accelerated ageing in all the six accelerated exposure tests, because of the stress relaxation effect as well as the influence of the initial conditons, the changes of M25 and M50 are relatively less than M100, M200 and M300. In most cases the differences among M100, M200 and M300 are not apparent. However, in the thermal oxidation, for CR and NR_C, the change of stress reaches the peak at the strain of $100 \%$, and then decreases rapidly. For NR_B the change of stress increases continuely with the strain. Besides, Fig.6(b) shows that in the ozone test although the stresses of NR_A change the greatest, they are less than 50\%. And NR_B changes the least. From Fig.6(e) and Fig.6(f), it is found that HDR is more easily influenced by salt water and acid rain than any other rubber materials. However, in the low-temperature ozone test HDR changes the least, as shown in Fig.6(c). Because the change of M100 is close to M200 and M300 in most cases, and they are not easily influenced by the residual strain caused by 


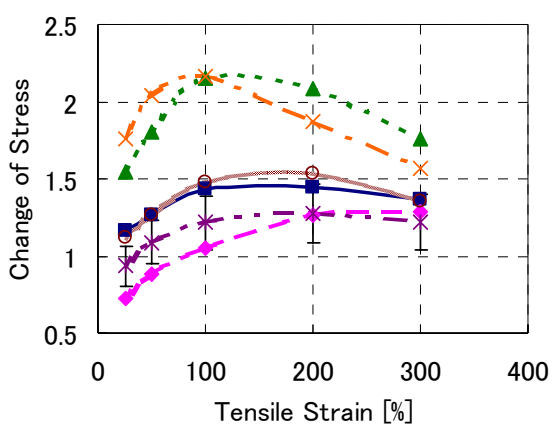

(a) Thermal oxidation $(1,536 \mathrm{~h})$

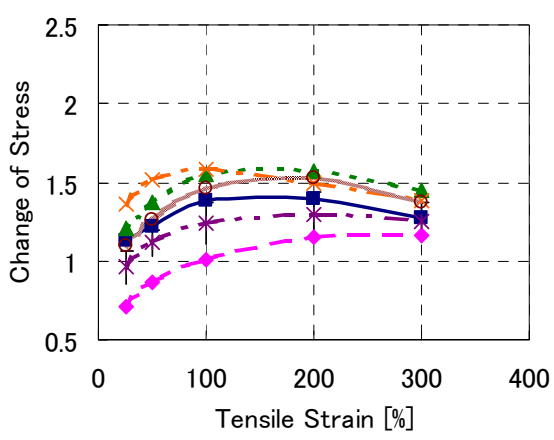

(d) Ultraviolet radiation $(1,440 \mathrm{~h})$ (NR_B, NR_C and CR at $720 \mathrm{~h}$ )

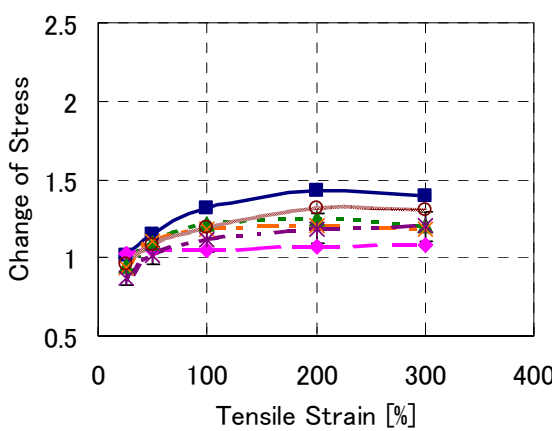

(b) Ozone $(1,536 \mathrm{~h})$ (EPDM at $768 \mathrm{~h})$

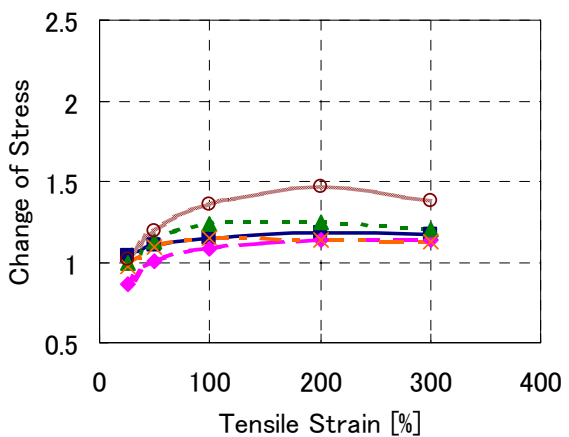

(e) Salt water combined cycle (1,440 h)

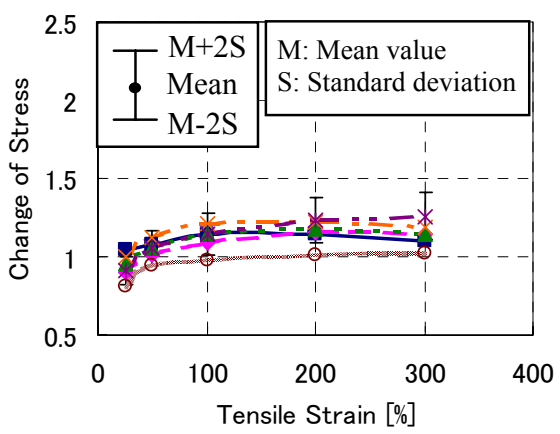

(c) Low-temperature ozone $(1,536 \mathrm{~h})$

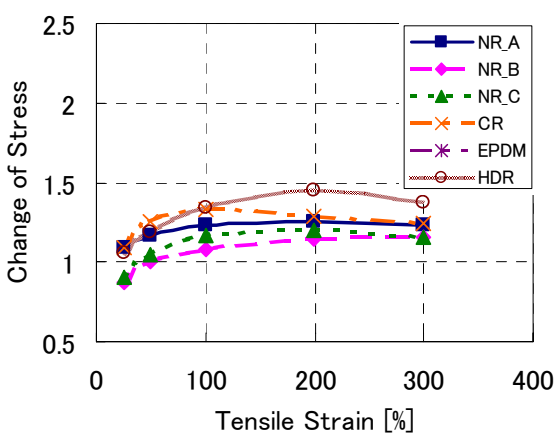

(f) Acid rain combined cycle (1,440 h)

Fig. 6 Strain dependency (pre-strain=40\%)

the pre-stress, for simplicity, in the following study, only M100 is taken as the index to evaluate the stiffness of rubber materials.

\section{(3) Influences of degradation factors}

Except for thermal oxidation test, other tests last about two months. Fig.7 compares the influences of different ageing factors on each rubber material at that time. The relative changes of M100, EB and TS are illustrated by taking the corresponding values in the virgin state as one.

Fig.7(a) shows that for NR_A, after about 2 months' deterioration, the thermal oxidation and the ultraviolet radiation change the material properties more than other degradation factors, with an increase of M100 by about $40 \%$ and a decrease of EB and TS by $40 \sim 50 \%$. The $40{ }^{\circ} \mathrm{C}$ ozone deterioration increases M100 by about $30 \%$, and decreases EB by $20 \%$, while almost no influence on TS. The $-30^{\circ} \mathrm{C}$ ozone deterioration only increases M100 by about $20 \%$, and does not influence either EB or TS, which means low temperature can retard the ozone ageing on NR_A to a certain degree. NR_A is more easily affected by acid rain than salt water. It shows a $20 \%$ change of properties due to the acid rain mist combined cycle.

In Fig.7(b), the M100 change of CR test pieces due to the thermal oxidation is the severest. M100 adds up to $220 \%$ due to the thermal oxidation, to nearly $160 \%$ due to the ultraviolet radiation, and EB drops to $60 \%$ and $70 \%$, respectively. Other degradation factors increase M100 to only about 120 $\sim 130 \%$ and decrease EB to over $80 \%$. It should be noticed that each degradation factor does not impact TS of CR.

From Fig.7(c), it is found that as for EPDM, the increases of M100 due to the thermal oxidation and the ultraviolet radiation are about $20 \%$, while due to the $40^{\circ} \mathrm{C}$ ozone and the $-30^{\circ} \mathrm{C}$ ozone are about $15 \%$. The decrease of EB and TS are about 10 20\%.

Fig.7(d) expresses the property changes of HDR. It is discovered that thermal oxidation almost has the same effect as ultraviolet radiation after 2 months, increasing M100 by $50 \%$, while decreasing EB by nearly $40 \%$ and TS by $20 \%$. Due to the ozone deterioration M100 rises by about $20 \%$ and EB descends by $20 \%$, but TS is unchanged. The lowtemperature ozone does not have any deterioration impact on HDR. Salt water and acid rain almost have the same effect on HDR, with an increase of M100 by $30 \%$ and a decline of EB by $20 \%$, but no impact on TS.

As for NR_B, M100 is almost not affected by any degradation factor, as shown in Fig.7(e). EB and TS are also not affected by all the factors except for thermal oxdiation and ultraviolet radiation. However, ultraviolet radiation decrease EB and TS greatly, showing a fall of $60 \%$ and $85 \%$, respectively. 
TO: Thermal oxidation UR: Ultraviolet radiation OZ: Ozone

EB: Elongation at break M100: Stress at $100 \%$ strain
LTOZ: Low-temperature ozone

SW: Salt water

AR: Acid rain

TS: Tensile strength

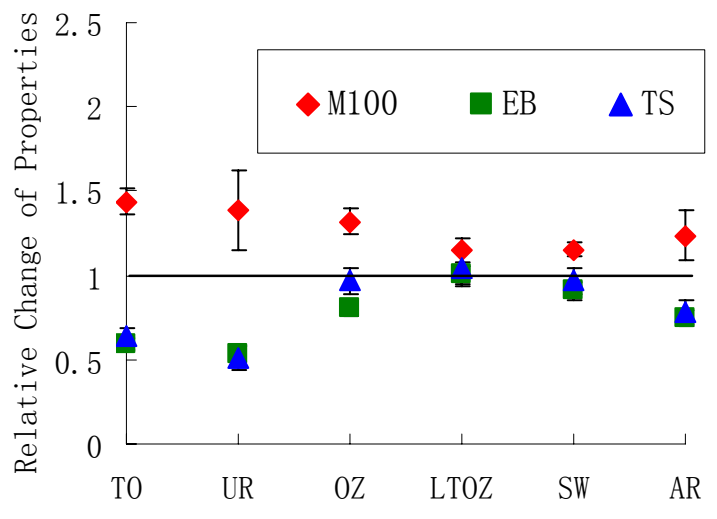

(a) NR_A

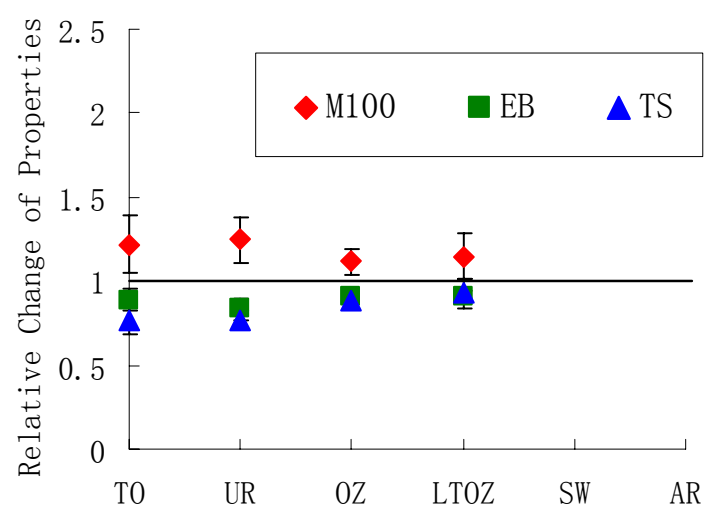

(c) EPDM (Ozone at $768 \mathrm{~h}$ )

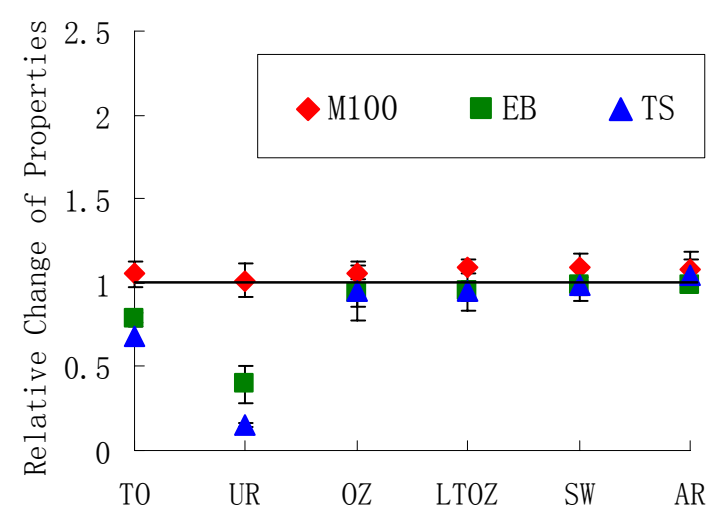

(e) NR_B (Ultraviolet at 720 h)

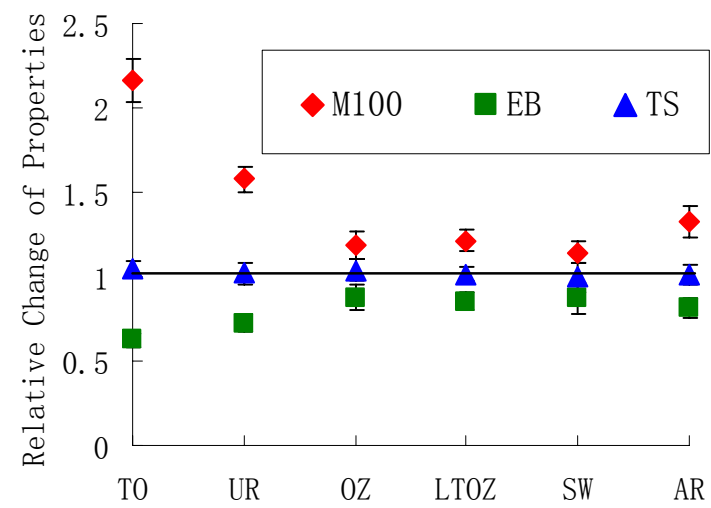

(b) CR (Ultraviolet at $720 \mathrm{~h}$ )

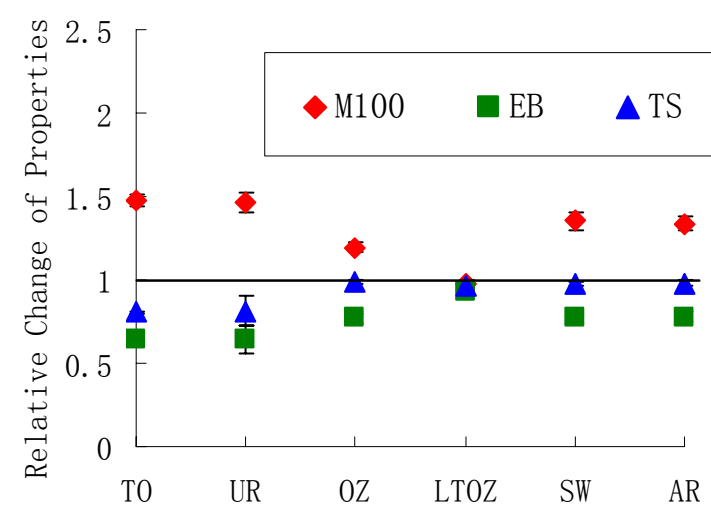

(d) HDR

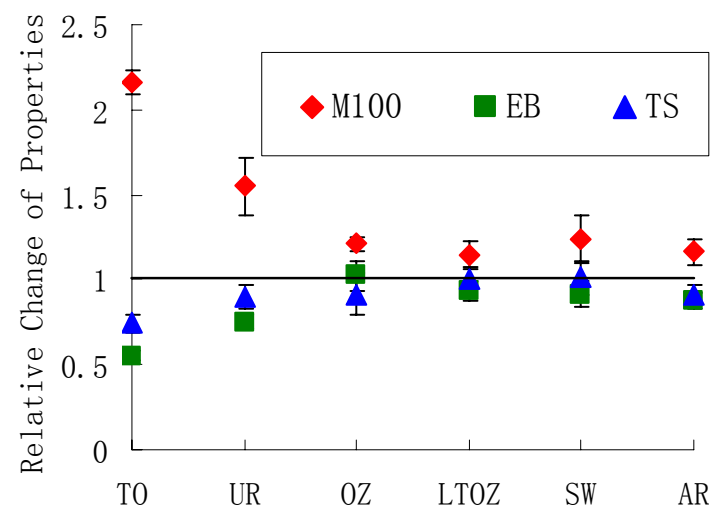

(f) NR_C (Ultraviolet at $720 \mathrm{~h}$ )

Fig. 7 Comparison between degradation factors ( 2 months, pre-strain $=40 \%$ )

Thermal oxidation reduces EB and TS by about 20 $30 \%$.

As illustrated in Fig.7(f), the property change tendency of NR_C are very close to that of CR. M100

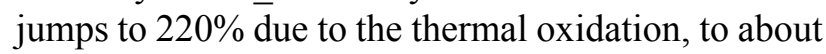
$160 \%$ due to the ultraviolet radiation. On the other hand, the $40^{\circ} \mathrm{C}$ ozone, $-30^{\circ} \mathrm{C}$ ozone, salt water and acid rain deterioration only increase M100 to about $120 \%$, and have little effect on EB and TS. The thermal oxidation decreases EB by about $40 \%$, TS by about $30 \%$. The ultraviolet radiation decreases EB by about $20 \%$, TS by about $10 \%$. 
Through investigating the relative changes of material properties due to each degradation factor until 2 months, it is found that rubber materials are usually more vulnerable to thermal oxidation and ultraviolet radiation than other factors, especially for CR and NR_C. In the ozone, low-temperature ozone, salt water and acid rain tests, the property changes of all the rubbers are usually within $30 \%$. For CR, HDR and NR_C, TS is almost not affected by these factors.

\section{(4) Ageing behavior of different rubber materials}

The relative changes of the rubber properties versus the ageing time are compared and plotted in Fig.8 $\sim$ Fig.13. Because the surface rubber contacting the ambient directly is in the tensile state, the results with the pre-strain of $40 \%$ are investigated. From a chemical point of view, along with the aggregation of new product, the reaction speed should slow down gradually.

From Fig.8, it is found that in the ozone, ultraviolet radiation and salt water mist combined cycle tests on NR_A, the deterioration curves of M100 tend to converge after 400 hours. However, in the thermal oxidation test this tendency is not found even after more than 6,000 hours. At that time M100 is already more than double of the initial value. EB and TS are only $25 \%$ of the virgin sample. Fig.8(c) proves that ozone in the low-temperature environment almost does not affect the properties of NR_A. In Fig.8(d), it is found EB and TS keep decreasing. At 1,440 hour EB and TS reduce to only about $50 \%$, even lower than those in the thermal oxidation test. The changes of M100 due to all the other degradation factors are less than $50 \%$. EB and TS also change little, with a decrease less than $25 \%$.

Fig.9 shows the property changes of CR. It can be observed that ozone, low-temperature ozone, salt water and acid rain deterioration change the properties of CR slowly. On the other hand, thermal oxidation increases M100 very rapidly and severely. As shown in Fig.9(a), after about 3,000 hours, M100 soars to over $250 \%$ and EB drops to about $50 \%$ due to the thermal oxidation. Besides, the tendency to the stable state is obvious. After 3,000 hours M100 and EB remains unchanged. For TS there seems no change from the very beginning. And from Fig.9(a) $\sim(f)$ it is found TS is not easily affected by any degradation factor. Fig.9(d) shows that the ultraviolet radiation changes M100 and EB of CR very fast too, which increases M100 by more than $50 \%$ and decreases EB by about $25 \%$ in 720 hours. Although the long-term behavior is not very clear in this test, the property change speed has already tended to be slower after 360 hours. Other factors increase M100 and decrease EB within 20\% after nearly 2 months' ageing, except the acid rain increases M100 by about $30 \%$.

In Fig.10, it is found that the property changes of EPDM due to all the degradation factors converge at the very early stage. The amount of property changes settles down gradually over the ageing time, and after nearly 400 hours the changes become very slight. Even the thermal oxidation does not increase M100 very much. As shown in Fig.10(a), after over 6,000 hours' ageing, M100 only increases 30\%, EB does not change much, however, TS decreases nearly $40 \%$. In other cases, the changes of M100, EB and TS are less than $25 \%$.

Fig.11 expresses the degradation effects on HDR. In Fig.11(a), the thermal oxidation test results are like NR_A, showing the continuous change of M100, EB and TS. At 6,144 hour, M100 is already 2.25 times of the initial value, and there are only $25 \%$ of $\mathrm{EB}$ and $50 \%$ of TS left. Ozone deterioration does not influence the HDR properties much, with an increase of M100 and a decrease of EB by about $20 \%$ after 1,536 hours, respectively. In the low-temperature ozone test, the material properties do not change at all (Fig.11(b), (c)). In the ultraviolet radiation test, after about 700 hours the increase speed of M100 slows down and approaches to 50\%, as shown in Fig.11(d). In the salt water mist combined cycle test, the stable state is reached in 400 hours. From Fig.11(e) it is found that M100 increases 35\%, and EB decreases $25 \%$, while TS seems to almost have no decrease by the end of the test. Fig.11(f) shows that the property changes due to the acid rain mist combined cycle are not very large, either. After 1,440 hours M100 increases $30 \%$, EB decreases $20 \%$, without change of TS.

As for NR B, the test results are illustrated in Fig.12. M100 changes slowly in the thermal oxidation test and only adds up to $130 \%$ after 6,144 hours. However, EB and TS decrease very rapidly and reduces to $40 \%$ and $20 \%$, respectively. As shown in Fig.12(d), the ultraviolet radiation is found to play an important role on NR_B. Although M100 almost does not change at all, EB and TS fall to $40 \%$ and $20 \%$ in 720 hours. At 1,440 hour, the specimens have already broken, so that the measured data cannot be obtained. In other figures, it can be seen that ozone, low-temperature ozone, salt water and acid have little influence on NR_B, and the changes of M100, EB and TS after 1,536 hours can hardly be found.

Comparing Fig.13 and Fig.9, it is discovered that the relative property changes of NR_C is very similar to $\mathrm{CR}$. Thermal oxidation changes the material properties greatly in spite of the little influence by other degradation factors. During the initial stages of the thermal oxidation test, the deterioration progresses very fast. Then as the time passes, the deterioration speed reduces gradually. M100 hardly 


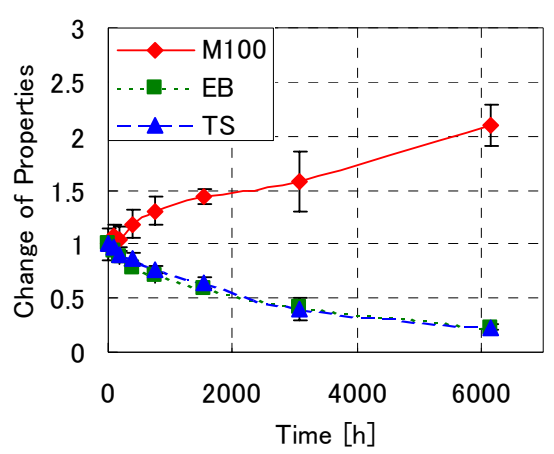

(a) Thermal oxidation

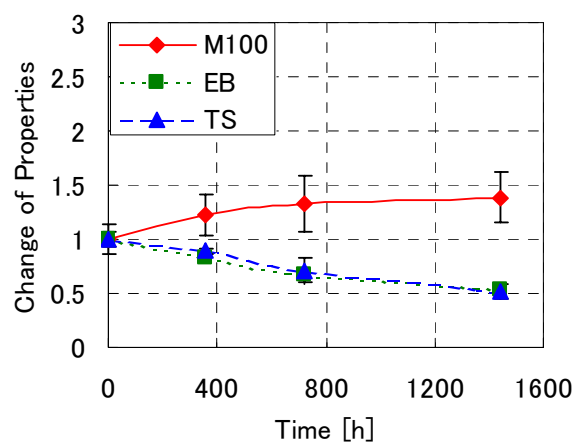

(d) Ultraviolet radiation

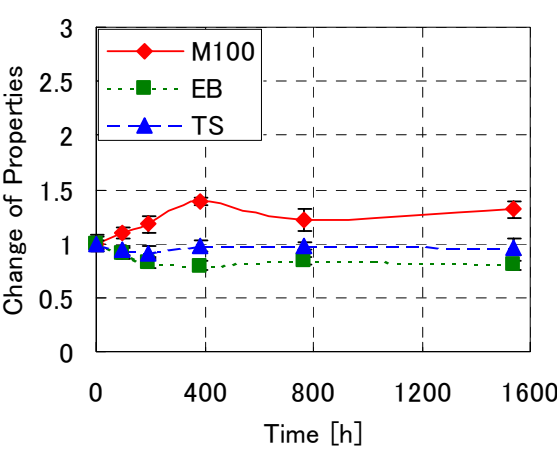

(b) Ozone

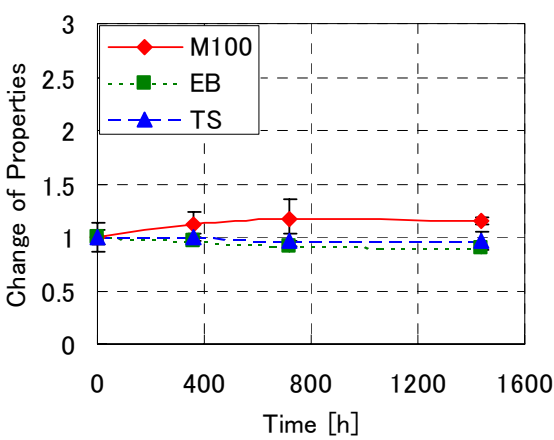

(e) Salt water combined cycle

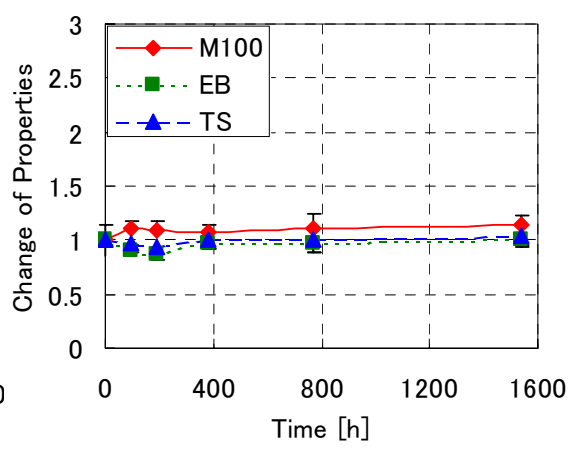

(c) Low-temperature ozone

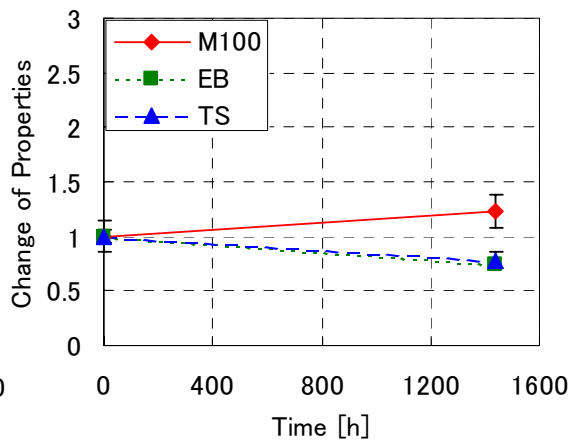

(f) Acid rain combined cycle

Fig. 8 Relative property changes of NR_A ( pre-strain $=40 \%$ )

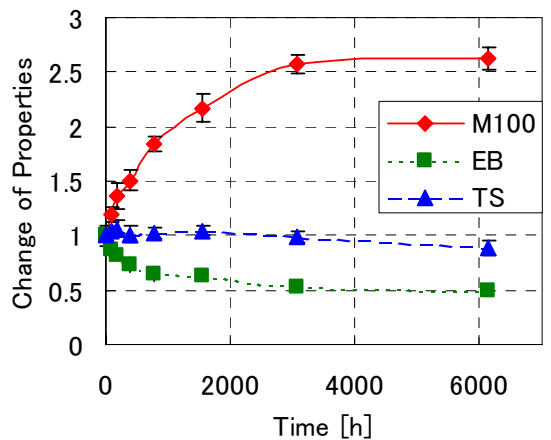

(a) Thermal oxidation

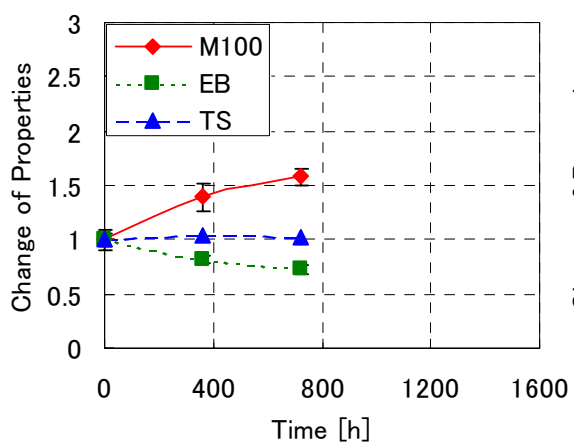

(d) Ultraviolet radiation

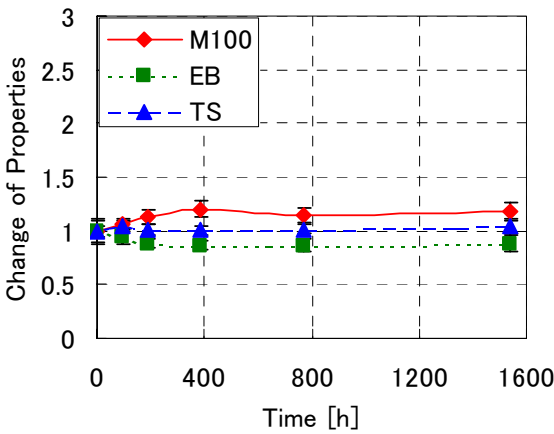

(b) Ozone

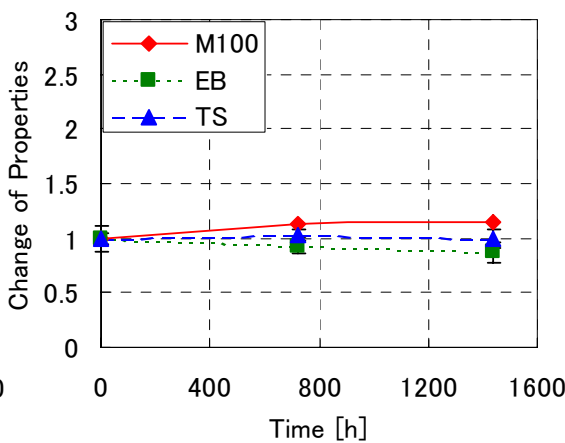

(e) Salt water combined cycle

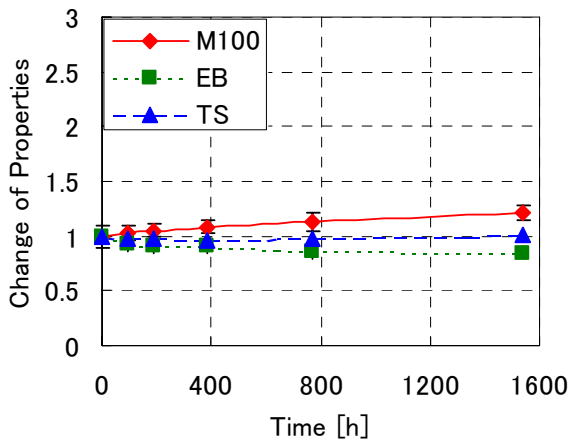

(c) Low-temperature ozone

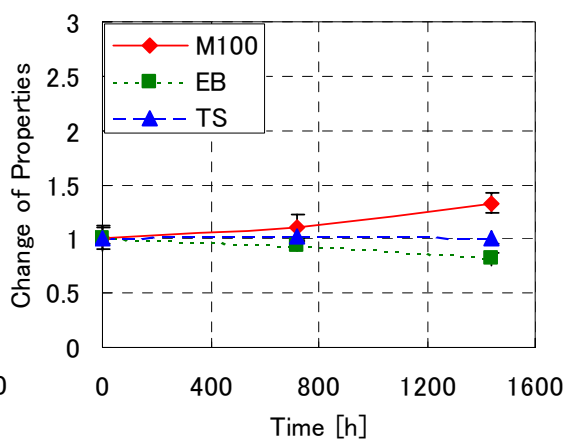

(f) Acid rain combined cycle

Fig. 9 Relative property changes of CR (pre-strain $=40 \%$ ) 


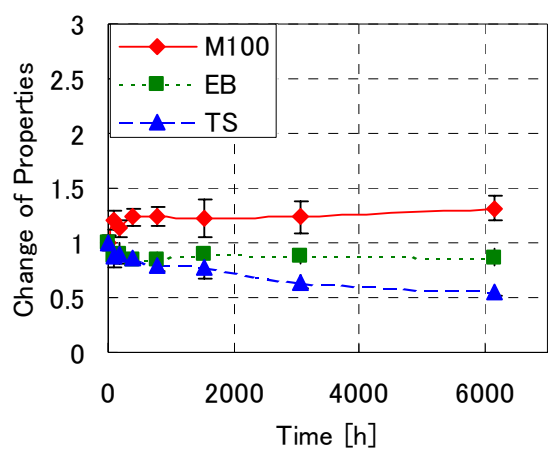

(a) Thermal oxidation

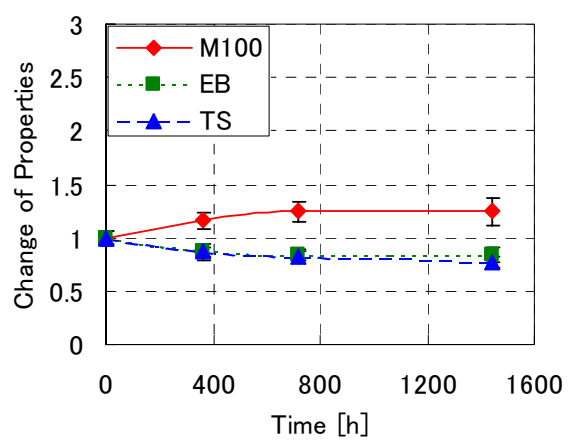

(d) Ultraviolet radiation

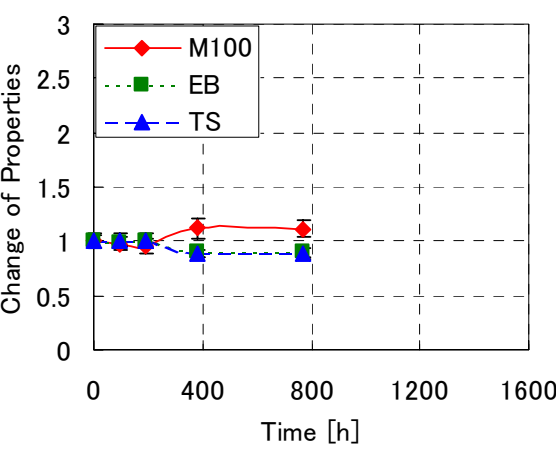

(b) Ozone

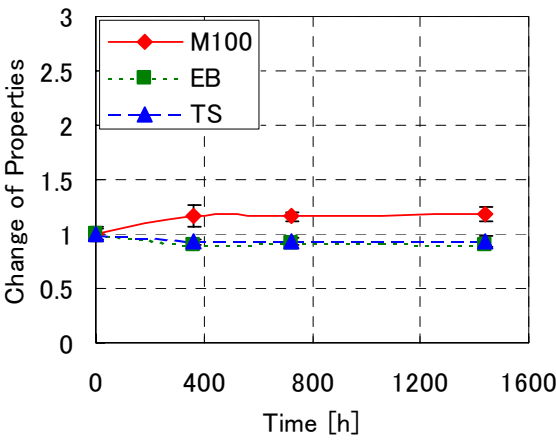

(e) Salt water combined cycle

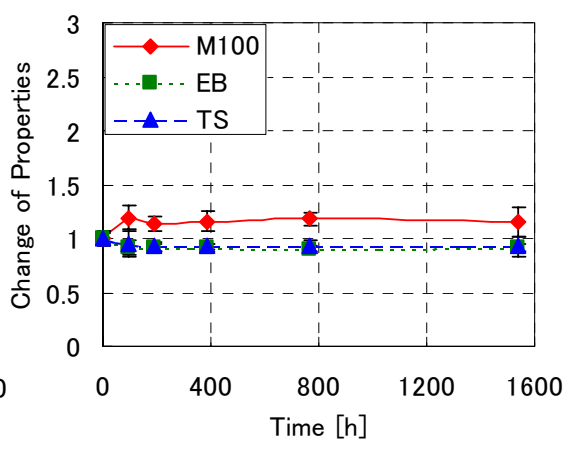

(c) Low-temperature ozone

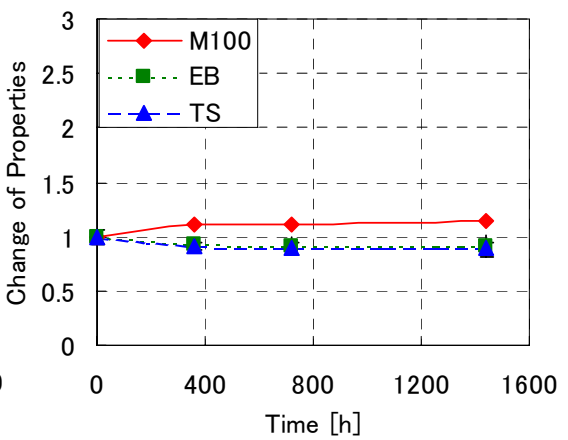

(f) Acid rain combined cycle

Fig. 10 Relative property changes of EPDM (pre-strain $=40 \%)($ In (e) and (f) pre-strain=0\%)

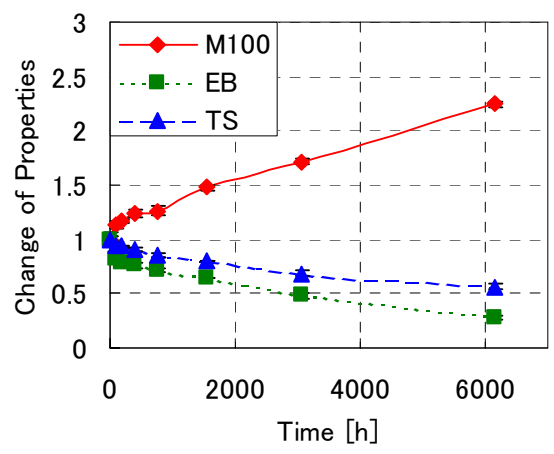

(a) Thermal oxidation

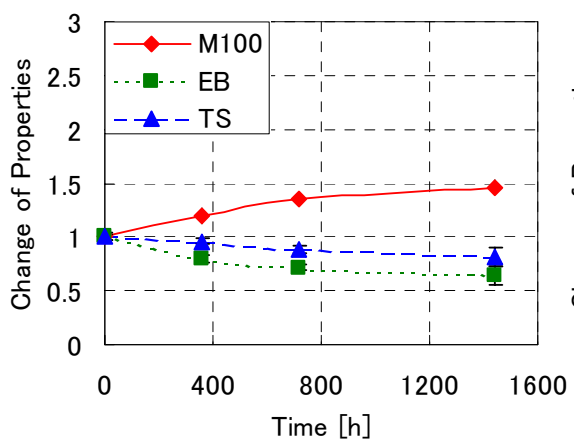

(d) Ultraviolet radiation

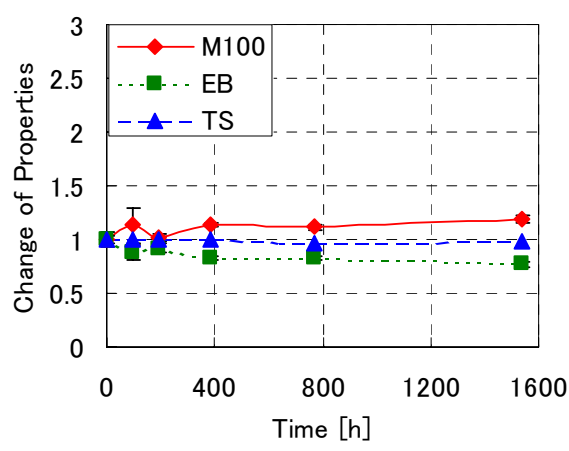

(b) Ozone

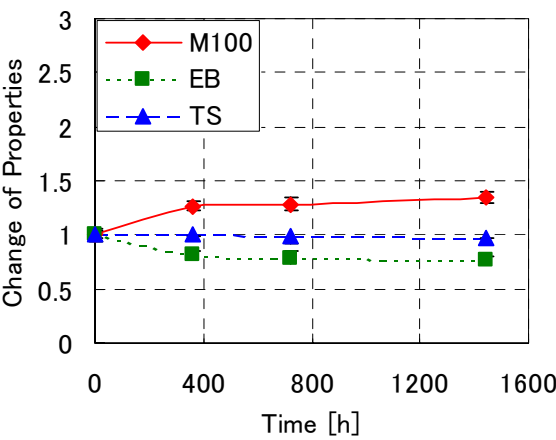

(e) Salt water combined cycle

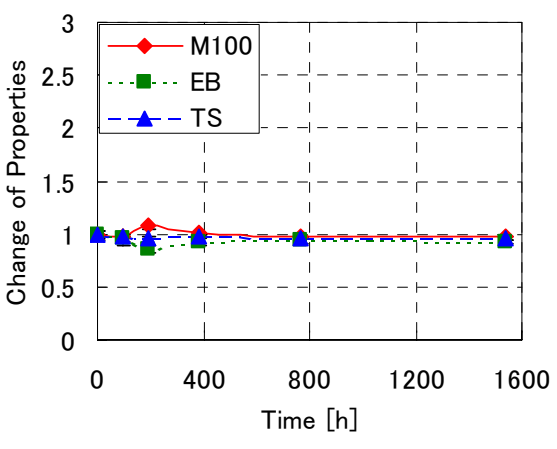

(c) Low-temperature ozone

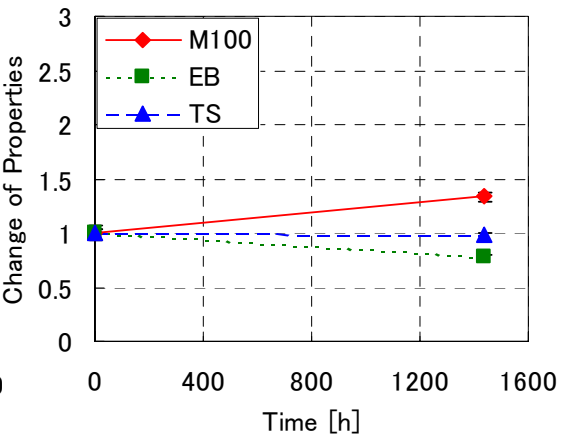

(f) Acid rain combined cycle

Fig. 11 Relative property changes of HDR (pre-strain $=40 \%$ ) 


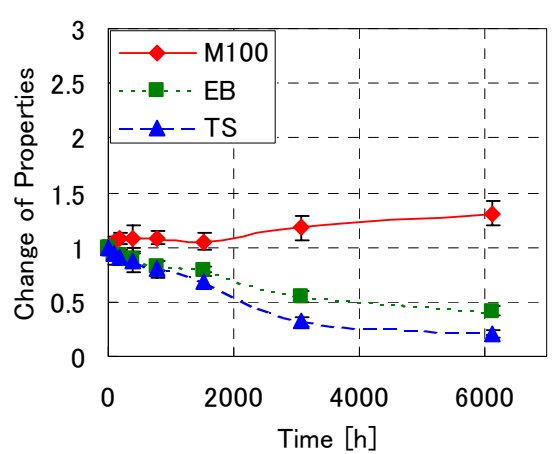

(a) Thermal oxidation

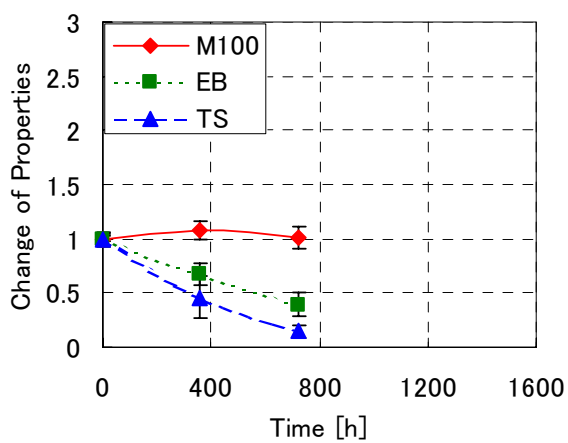

(d) Ultraviolet radiation

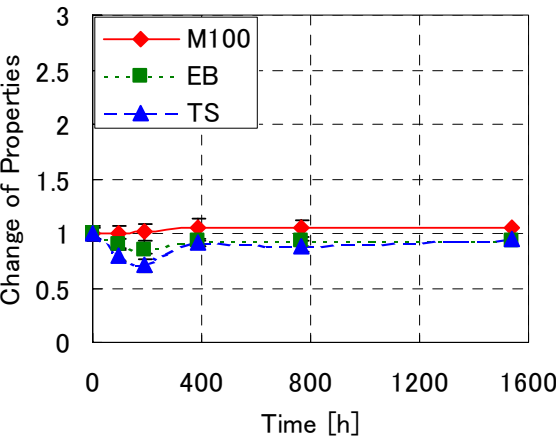

(b) Ozone

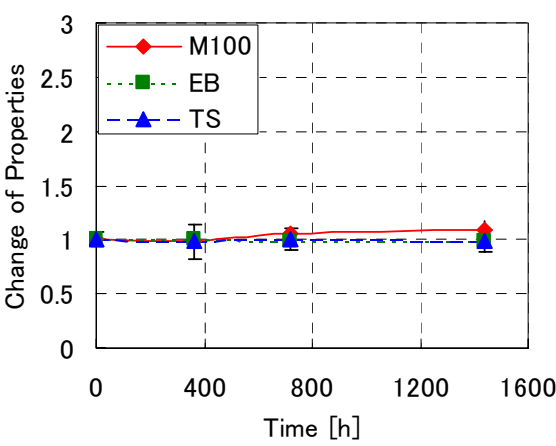

(e) Salt water combined cycle

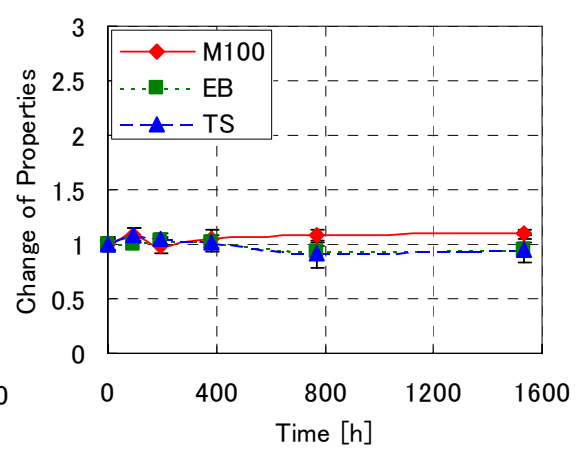

(c) Low-temperature ozone

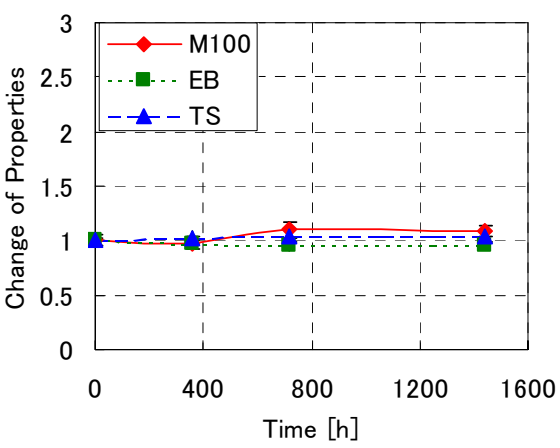

(f) Acid rain combined cycle

Fig. 12 Relative property changes of NR_B (pre-strain = 40\%)

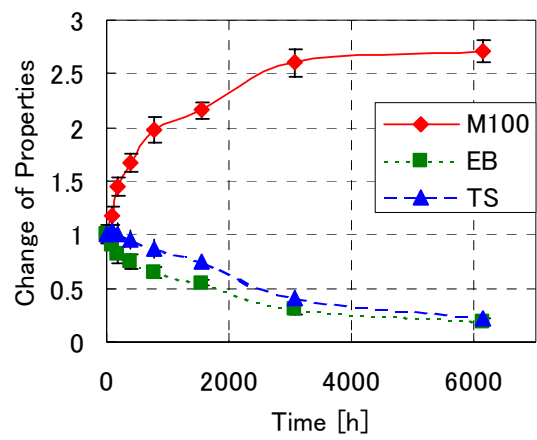

(a) Thermal oxidation

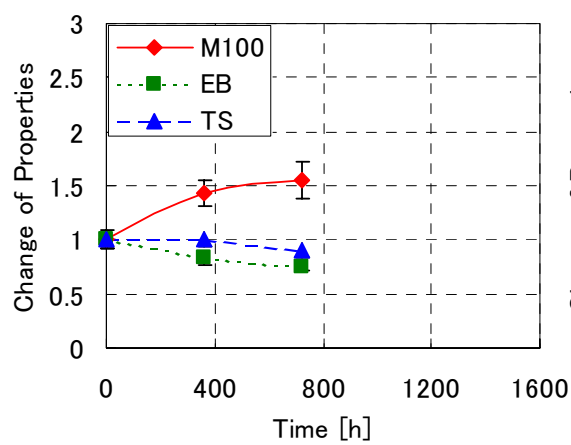

(d) Ultraviolet radiation

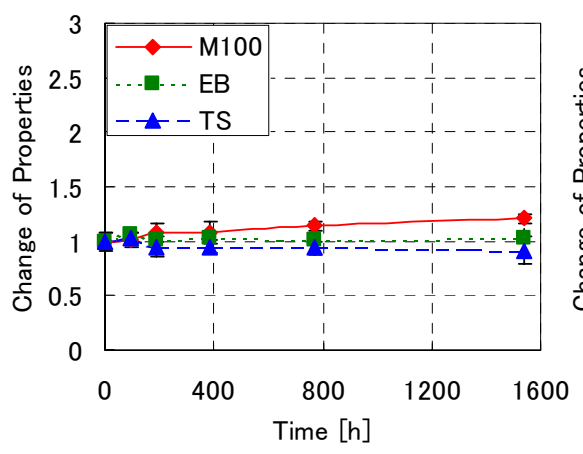

(b) Ozone

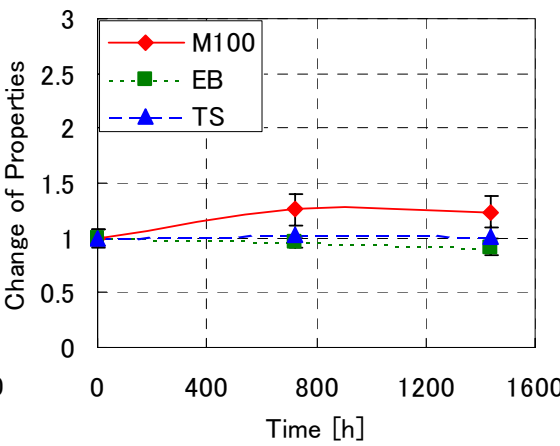

(e) Salt water combined cycle

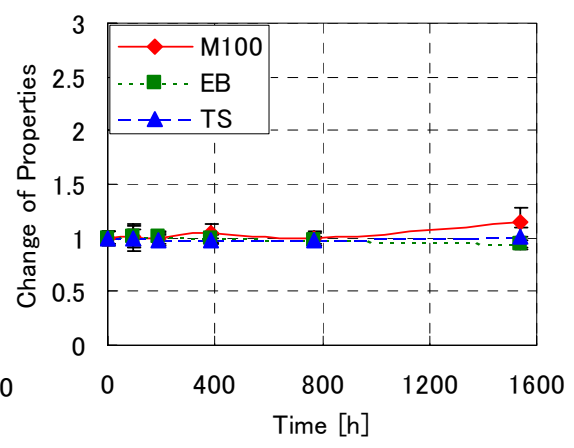

(c) Low-temperature ozone

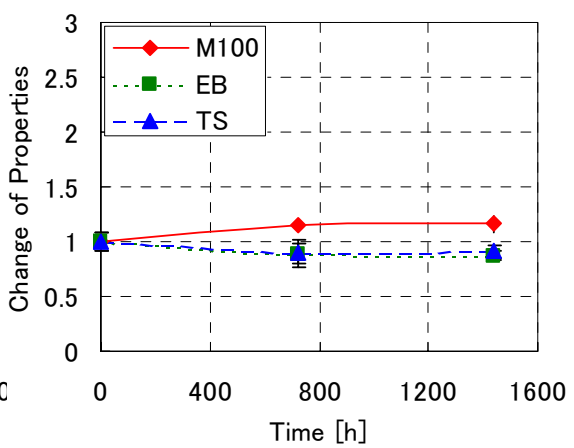

(f) Acid rain combined cycle

Fig. 13 Relative property changes of NR_C (pre-strain $=40 \%)$ 
increases after about 3,000 hours, after jumping to about $270 \%$ of the virgin sample. EB and TS continue decreasing and fall by about $80 \%$ after 6,144 hours. The $40^{\circ} \mathrm{C}$ ozone deterioration increases M100 by $20 \%$ and decreases TS by $10 \%$, but does not change EB. When combined with low temperature, the ozone almost has no ageing effect on material properties. Although the ultraviolet radiation also increases M100 very fast, like CR, after 400 hours the tendency to converge has already appeared. At 720 hour, M100, EB and TS are 50\%, $75 \%$ and $90 \%$ of the initial values, respectively. In the salt water and the acid rain mist combined cycle tests, the changes of the material properties converge after nearly 700 hours. The final changes of M100 are less than $25 \%$, EB and TS are less than $15 \%$.

On the whole, thermal oxidation affects rubber properties much greater than other factors such as ozone, ozone in low temperature, salt water and acid rain. Ultraviolet radiation also changes material properties greatly. In most cases, the progress of deterioration becomes slower and slower over the ageing time. The property changes tend to converge when deterioration reach a certain degree. The increases of M100 and the decreases of EB and TS due to ozone, low-temperature ozone, salt water or acid rain are mostly usually less than $30 \%$. However, thermal oxidation can increase M100 by more than $100 \%$ except for EPDM and NR_B. In addition, only oxidation is considered to be able to affect the inner part of thick rubber, thus it is reasonable to deem the thermal oxidation as the most significant degradation factor. Moreover, because of the different additives to NR, the differences between NR and other rubber materials are not very clear. The deterioration characteristics of NR_A and NR_B are similar to that of HDR, and NR_C is like CR.

\section{(5) Effect of pre-strain}

In the accelerated ageing tests, three kinds of strain states are investigated. They are tensile strains of $0 \%$, $20 \%$ and $40 \%$, to which the rubber specimens are stretched and kept throughout the ageing tests. The comparisons of the pre-strain effects on M100, EB and TS are shown in Fig.14. Here, the relative changes are illustrated by taking the corresponding values in the virgin state as zero. It is found that the long-term mechanical properties of rubbers are partially related to their strain state during the ageing processes.

Fig.14(a) shows the pre-strain effects on NR A. In most cases, the variations due to the pre-strain are not obvious. However, in the acid rain mist combined cycle test, the $40 \%$ pre-strain has significant influence on EB and TS, showing the changes of the properties increase by several times.
As for CR shown in Fig.14(b), there seems no clear relation between the pre-strain and the deterioration due to thermal oxidation and the salt water. In the ultraviolet radiation test, the increase of M100 with the $40 \%$ pre-strain is nearly twice of the change without the pre-strain. In the acid rain test, this rate can reach more than 4 times and the decrease of EB with the $40 \%$ pre-stain is 2.5 times of that without the pre-strain.

From Fig.14(c), it is found that in the thermal oxidation test, the pre-strain could reduce some ageing effects on EPDM. After 6,144 hours, the increase of M100 with the $40 \%$ pre-strain is only $1 / 3$ of the change without the pre-strain, and the decrease of EB is reduced by half. In other accelerated exposure tests, the effect of the pre-strain is too vague to be found.

The pre-strain effect on the deterioration of HDR is shown in Fig.14(d). The same as EPDM, the pre-strain of $40 \%$ reduces the increase of M100 due to the thermal oxidation from $200 \%$ to $125 \%$. EB and TS do not seem to be affected. In the ozone test, the low-temperature ozone test, the salt water and the acid rain mist combined cycle test, the pre-strain strengthens the ageing effects, making M100 increase more, EB decrease more. Especially in the ozone test, EB decreases by more than 4 times, and M100 increases by nearly twice. In the acid rain mist combined cycle test, the change of M100 and EB with the $40 \%$ pre-strain is more than twice of that without pre-strain.

In Fig.14(e), in spite of the irregularity of variation in the ozone deterioration test, it is clear that the pre-strain causes EB and TS to change more, but M100 to change less in the thermal oxidation test. The $40 \%$ pre-strain makes the change of M100 decrease from $75 \%$ to $30 \%$. However, the decrease of EB changes from $30 \%$ to $60 \%$, and TS from $50 \%$ to about $75 \%$. The pre-strain in the ultraviolet radiation test also has the same tendency as in the thermal oxidation test, with the increase of M100 falling from about $20 \%$ to almost $0 \%$, the decrease of EB changing from nearly $20 \%$ to $60 \%$ and TS from $25 \%$ to more than $80 \%$.

Fig.14(f) expresses the pre-strain effects on the deterioration of NR_C. Pre-strain seems to have little influence on the deterioration. Only in the acid rain mist combined cycle tests, it can be observed that $40 \%$ pre-strain worsen the deterioration through increasing the changes of EB and TS.

In general, the pre-strain will strengthen the ageing effects in most cases, by causing the material properties to change more. Especially in the acid rain mist combined cycle test, this change can be several times. However, in the thermal oxidation, for EPDM, HDR, NR_B and NR_C, the increases of M100 are 


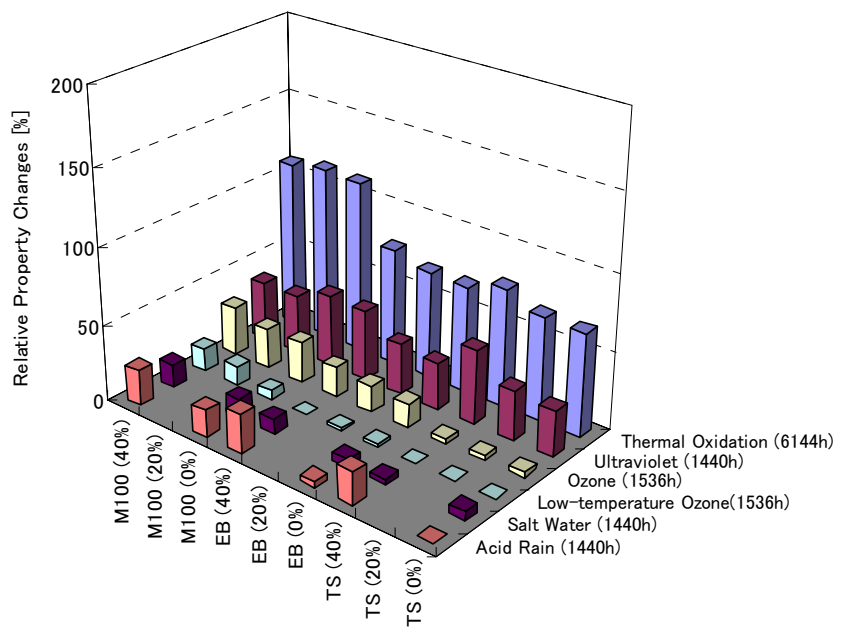

(a) NR_A

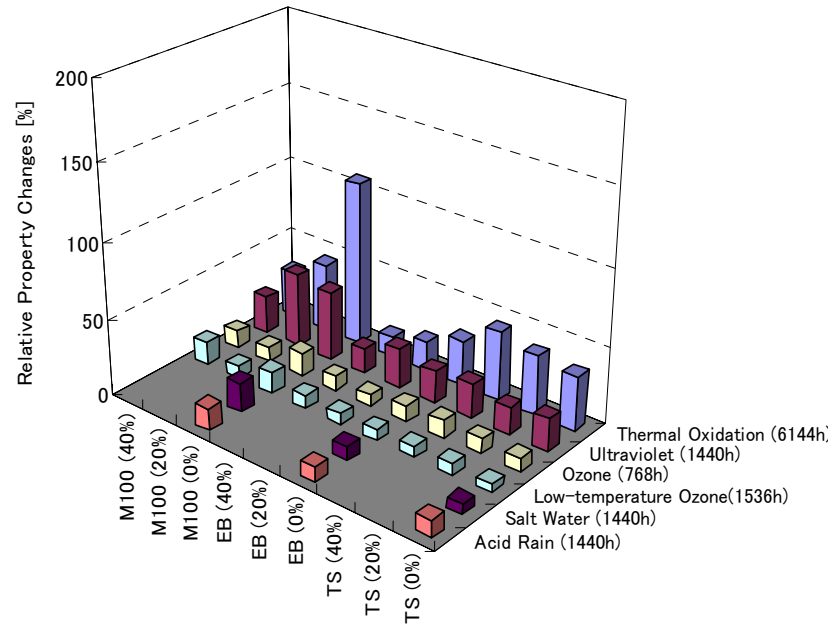

(c) EPDM

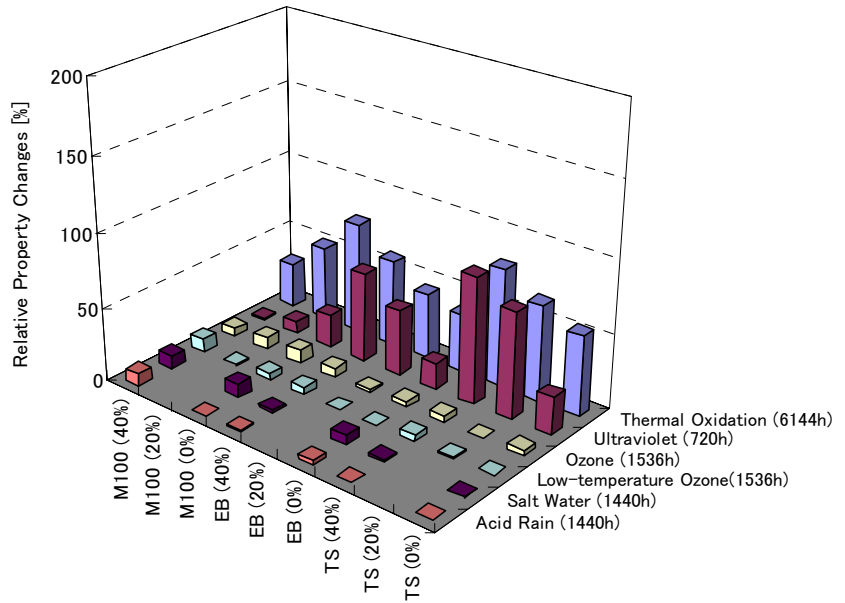

(e) NR B

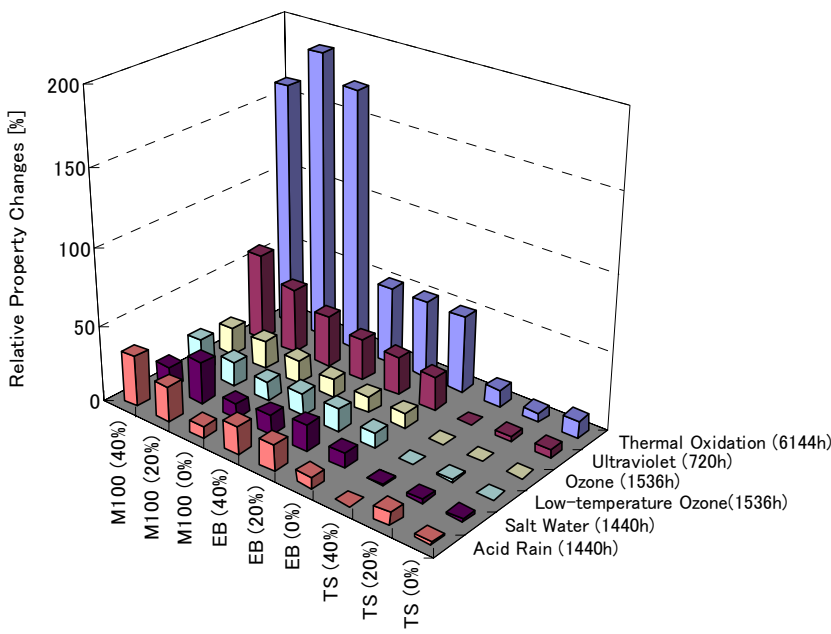

(b) $\mathrm{CR}$

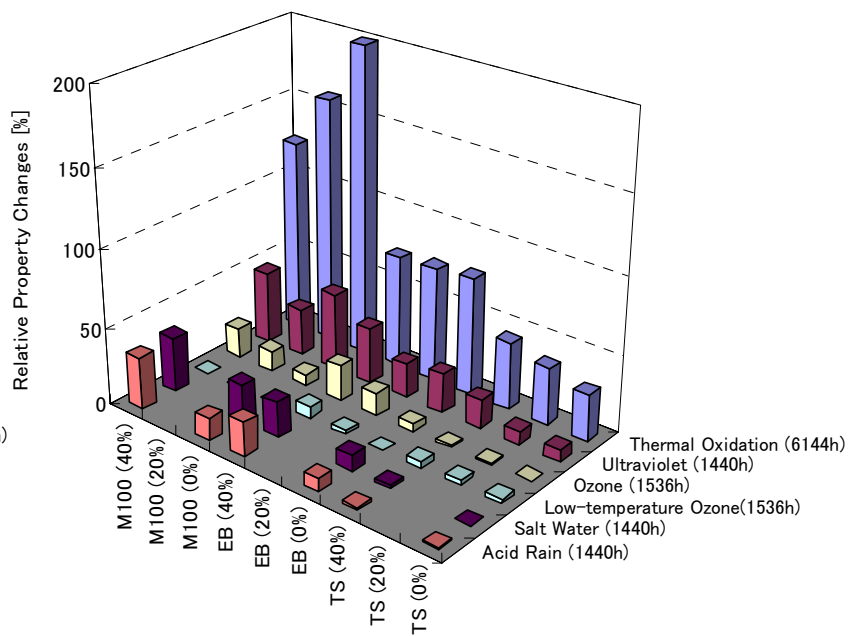

(d) HDR

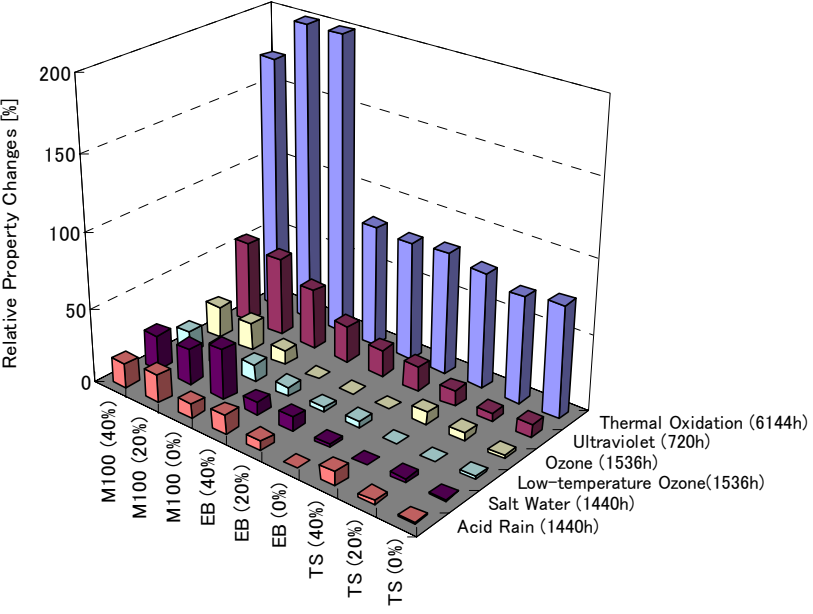

(f) NR_C

Fig. 14 Effect of pre-strain on mechanical properties 
found to be lessened by the pre-strain. Because the thermal oxidation is the predominant degradation factor, the effects of the pre-strain will be significant in absolute value. Since the surface rubber is in the tensile state, the pre-strain will behave its favorable aspect by reducing the stiffness increase due to oxidation. Attention should be paid to this phenomenon.

\section{APPLICATION OF TEST RESULTS}

The accelerated exposure test results can be used to predict the mechanical behaviors of rubbers in the real environment. For example, in order to accelerate the deterioration, the temperature in the thermal oxidation test is much higher than the temperature in the real environment. Using the Arrhenius therory ${ }^{14)}$, the relationship between the deterioration time in the accelerated exposure test and the time in the real environment can be established. Gerenally the thermal oxidation is assumed as the $1^{\text {st }}$ chemical reaction for rubber materials. Then the deterioration time in the accelerated exposure tests can be converted into the real environmental conditions through the following formula:

$$
\ln \left(\frac{t_{r}}{t}\right)=\frac{E_{a}}{R}\left(\frac{1}{T_{r}}-\frac{1}{T}\right)
$$

where, $E_{a}$ is the activation energy of the rubber, $R$ is the gaseous constant $(=8.314[\mathrm{~J} / \mathrm{mol} \cdot \mathrm{K}]), T_{r}$ indicates the absolute temperature in the real environment, and $T$ is the absolute temperature in the thermal oxidation test. The symbols $t_{r}$ and $t$ are the real time and test time, respectively.

However, it should be noticed that the long-term accelerated exposure tests in this research only focuses on the ageing behaviors on the surfaces of the bridge rubber bearings. Because aged rubber will prevent deterioration from progressing into the inner rubber bearing, the properties from the surface to the interior of the aged rubber bearing are not uniform ${ }^{15}$. It is easier for oxidation to penetrate the covering rubber than other factors. Therefore, the property variation due to the thermal oxidation inside the rubber bearing is worth studying further. The related research will be introduced in other papers. When the aging behaviors of the whole rubber bearings are made clear, the long-term mechanical properties of the bridge bearing might be predicted.

\section{CONCLUSIONS}

A series of long-term accelerated exposure tests are performed in order to evaluate the durability of some rubbers usually used for bridge bearings. The mechanical property changes of four kinds of rubbers, Natural Rubber (NR), Chloroprene Rubber (CR), Ethylene-Propylene Rubber (EPDM), and High Damping Rubber (HDR), and the influence of the pre-strain are investigated in six different environmental conditions: thermal oxidation, ozone, low-temperature ozone, ultraviolet radiation, salt water and acid rain. Major findings and conclusions are summarized as follows:

1) Normally the stresses corresponding to certain strains increase over the ageing time while the elongation at break and the tensile strength decrease. These deterioration effects can not only weaken the function of the bridge bearings to isolate the superstructure and absorb energy, but also reduce the safety factor. Therefore, it is needed to consider the deterioration of the rubber bearing during the design and maintenance stages.

2) The thermal oxidation is discovered to be the most significant degradation factor, due to which the stress corresponding to $100 \%$ strain (M100) of most rubbers experiences an increase of $100 \% \sim 200 \%$ over long time.

3) The deterioration progress tendency of each examined rubber in various environments is made clear. For those insignificant degradation factors the stable state is reached in the early time and the property changes are usually less than $50 \%$. The test results in this paper only depict the ageing behaviors of rubbers on bearings' side surface. It is thought difficult for those insignificant factors to influence the inner part of the rubber bearing.

4) The stiffness of Chloroprene Rubber (CR) and Natural Rubber of Company C (NR_C) increase the greatest in the thermal oxidation test, to over 2.5 times of the original value. Compared with other rubbers, Ethylene-Propylene Rubber (EPDM) is relatively uneasy to be deteriorated, showing the changes of all the properties below $40 \%$.

5) The test results show that Natural Rubber (NR) behaves different deterioration characteristics according to its additives.

6) Pre-strain is proved to partially influence the ageing behaviors of rubbers. In most cases, pre-strain strengthens the ageing effect. However, for Ethylene-Propylene Rubber (EPDM), High Damping Rubber (HDR), Natural Rubber of Company B and C (NR_B 
and NR C), the existance of the pre-strain can counteract a part of ageing effect caused by the thermal oxidation through reducing the increase of M100. When used for bridge bearing, these rubbers will have longer life-spans.

7) Based on the results of the accelerated exposure tests, the property changes of bridge rubber bearings in service might be predicted using the Arrhenius theory. And combined with the tests investigating the deterioration inside the rubber bearing, it will be possible to predict the long-term mechanical behaviors of the bridge rubber bearing.

ACKNOWLEDGMENT: The authors wish to express their gratitude to Oiles Co., Tokai Rubber Industries, Ltd., Bridgestone Co., Yokohama Rubber Co., Ltd., and Kawaguchi Metal Industries Co., Ltd. for support with the long-term accelerated exposure tests. The study presented in this paper was supported by the Grants-in-Aid for Scientific Research of Ministry of Education, Culture, Sports, Science and Technology, Grant No.1560237, and the research leader is Prof. Yoshito Itoh. The support is gratefully acknowledged.

\section{REFERENCES}

1) Blackman, E.J. and McCall, E.B.: Relationship between the structures of natural rubber vulcanizates and their thermal and oxidative aging, Division of rubber chemistry, Rubber Chemistry and Technology, Buffalo, New York, October 14-17, pp.651-661, 1969.

2) Braden, M. and Gent, A.N.: The attack of ozone on stretched rubber vulcanizates. I. The rate of cut growth, Journal of Applied Polymer Science, Vol. 3, pp. 90-100, 1960.

3) Sugimoto, H., Mizoe, M., Yamamoto, Y. and Ikenaga M.: Research on low temperature resistance of the natural rubber bearing, Journal of Structure Mechanics and Earthquake Engineering, JSCE, No.693/VI-53, pp.73-86, 2001 (in Japanese).

4) Koike, M., Tanaka, K. and Hioki, S.: Weatherability of elastomeric roofing membranes, Journal of Asian Architecture \& Building Engineering, A.I.J., No.285, pp.15-22, 1979 (in Japanese).

5) Song, M.S., Hu, G.X. and Hu, L.J.: Prediction of long-term mechanical behaviour and lifetime of polymeric materials, Polymer Testing, Vol. 17, pp.311-332, 1998.

6) Wei, Y. T., Nasdala, L., Rothert, H. and Xie, Z.: Experimental investigations on the dynamic mechanical properties of aged rubbers, Polymer Testing, pp. 447-453, 2004.

7) Tobolsky, A.V.: Properties and structure of polymers, Wiley, New York, 1960.

8) Zlata, H. M. and Jasenka, J.: Change of network structure of natural rubber vulcanizate with thermal aging, Macromolecular Materials and Engineering, No.283, pp.21-25, 2000.

9) Itoh, Y., Yazawa, A., Satoh, K., Gu, H.S., Kutsuna, Y. and Yamamoto, Y.: Study on environmental deterioration of rubber material for bridge bearings, Journal of Structure Mechanics and Earthquake Engineering, JSCE, No.794/I-72, pp.253-266, 2005 (in Japanese).

10) Japan Highway Public Corporation: Guideline of proof test of rubber, 1999 (in Japanese).

11) Japan Road Association: Method of test for rubber bearing, 2004 (in Japanese).

12) Itoh, Y., Yazawa, A., Kitagawa, T., Kainuma, S., Yamamoto, Y. and Kutsuna Y.: Study on environmental durability of rubber bearing for bridges, IABSE Symposium, Melbourne, pp.268-269, 2002.

13) Grassie, N. and Scott, G.: Polymer degradation \& stabilization, Cambridge University Press, 1985.

14) Le, Huy, M. and Evrard, G.:Methodologies for lifetime predictions of rubber using Arrhenius and WLF models, Die Angewandte Makromolekulare Chemie, Vol.261/262, pp.135-142, 1998.

15) Celia, M., Wise, J., Ottesen, D. K., Gillen, K. T. and Clough, R. L.: Correlation of chemical and mechanical property changes during oxidative degradation of neoprene, Polymer Degradation and Stability, Vol. 68, pp. 171-184, 2000.

(Received April 11, 2005) 